\section{THE IMPORTANCE of Self-Narration IN RECOVERY FROM AdDICTION}

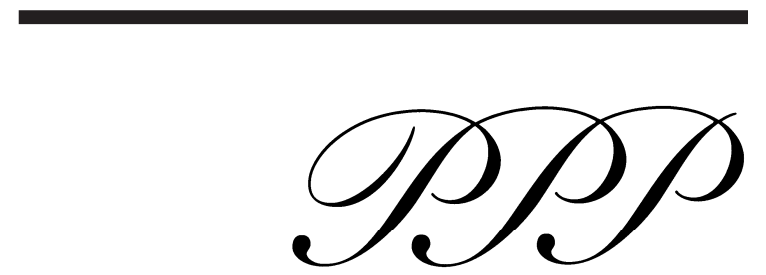

\begin{abstract}
AвSTRACT: Addiction involves a chronic deficit in selfgovernance that treatment aims to restore. We draw on our interviews with addicted people to argue that addiction is, in part, a problem of self-narrative change. Over time, agents come to strongly identify with the aspects of their self-narratives that are consistently verified by others. When addiction self-narratives become established, they shape the addicted person's experience, plans, and expectations so that pathways to recovery seem to be implausible and feel alien. Therefore, the agent may prefer to enact her disvalued self-narrative because at least it represents who she takes herself to be. To recover, the agent needs to conduct narrative work, adjusting her existing self-narrative so that it better supports recovery-directed narrative projections. Reducing cravings, managing withdrawals, increasing self-control, and developing goals are all important for recovery, but those approaches will often be in vain if the influence of self-narrative is ignored. If our analysis is correct, addiction treatment will typically be more effective if it incorporates support for self-narrative change.
\end{abstract}

KeYwords: Narrative, self-governance, autonomy, alienation

$\mathrm{T}$ HE FIRST-HAND reports of addicted people and the obvious misery they cause themselves make it clear that these people struggle to live according to their values. ${ }^{1}$ The goal of treatment is to help these people develop

\section{Doug McConnell \& AnKe SnOEK}

the agential resources to live a life they would value more highly. Sadly, most addicted people who seek treatment relapse repeatedly, often over several years, and despite multiple cycles of treatment; some never recover (Brandon, Vidrine, \& Litvin, 2007; Dennis, Scott, Funk, \& Foss, 2005; Stanford, Banerjee, \& Garner, 2010). However, the fact that some do recover, sometimes quite quickly, generates hope that efficient treatment can become more widespread (Heyman, 2009). Any improvement in treatment efficiency will have a significant payoff given that addicted people typically do extensive damage to themselves, their friends and family, and wider society during their struggles to recover (Birnbaum et al., 2011; Mohapatra, Patra, Popova, Duhig, \& Rehm, 2010; Orford, Velleman, Natera, Templeton, \& Copello, 2013). In this paper, we draw on our qualitative interviews with addicted people to explain why addiction is, in part, a problem of self-narrative change and why treatment will be more efficient if it supports that change.

We build on a lineage of research claiming that recovery requires or is promoted by a change in self-concept (Biernacki, 1986; Kellog, 1993; Shadel, Mermelstein, \& Borelli, 1996; Shinebourne \& Smith, 2009; Walters, 1996), or, more specifically, a change in self-narrative (Hänninen 
\& Koski-Jännes, 1999; Koski-Jannes, 2002; McConnell, 2016; McIntosh \& McKeganey, 2000). However, the existing research is largely descriptive and so a skeptic might believe that changes in self-concept or self-narrative do not drive recovery, but merely reflect it. If this is true, then treatment should not focus on self-conceptual or self-narrative change, but on the real causes of addiction whatever they may be. Some empirical research speaks against such skepticism, however. West (2006) reports that identifying as an ex-smoker a week after quitting predicted abstinence 6 months later. Similarly, Dunlop and Tracy (2013) found that recovering alcoholics who, at baseline, narrated their last drink as part of a positive story of adaptive self-change were more likely to be sober at follow-up than those who did not tell such stories at baseline. But why would self-conceptual or self-narrative change itself be difficult and why would some manage to make the necessary changes and others not? Without a plausible explanation of how self-concepts or self-narratives influence recovery, the skeptic might worry that the effects associated with self-narratives are actually caused by one or more confounding variables. We develop a response to this skeptical concern by outlining the ways in which self-narratives plausibly influence recovery. We argue, with support from our interviews, that the cumulative, socially mediated process of self-narration leads addicted people to identify with their disvalued self-narratives, and both the addicted person and their peers to treat those disvalued narratives as factual. Therefore, people tend to enact their self-narratives even as they disvalue them. Furthermore, disvalued self-narratives cannot simply be switched for more valued self-narratives, because any new self-narrative content that fails to cohere with the established self-narrative will feel alien to the addicted person and seem to be implausible both to herself and her peers.

The paper is structured as follows: First, we sketch our favored accounts of self-narration and the relationship between self-narration and self-governance. Second, we outline the methodology of our qualitative study. Third, we draw on examples from our interviews to illustrate the motivational effects of self-narratives in the con- text of addiction. Finally, we argue that the selfnarrative effects we have identified are likely to be particularly pervasive and influential in addiction and so should be given widespread consideration in treatment.

\section{Narrative Self-Constitution AND SElF-GovernanCE}

Narratives render events meaningful by specifying the causal, teleological, or thematic connections between them (Schechtman, 2007). Therefore, they are more than just lists of events; however, they need not meet the stronger aesthetic requirements of novels or films so they can be banal and include extraneous material. In selfnarration, the agent specifies meaningful connections between events (experienced, anticipated, or possible) that she judges to be relevant to her life. This process involves building narrative connections between her plans, desires, and contingent circumstance-for example, working out which actions make sense given the circumstance and which outcome each action will lead to. Therefore, a self-narrative is a way of describing part of a person's self-concept; it specifies the meaningful connections that the agent makes between her beliefs, desires, plans, values, and so on. Selfnarration is selective, that is, it focuses the mind on particular relations between events, clearing the mind of other possibilities that would otherwise by overwhelming (Mackenzie \& Poltera, 2010). Human life involves diverse experiences, values, and goals, so the agent does not, typically, try to connect everything in her life into a single coherent story but rather, she develops a collection of many partially overlapping, partially interconnected narrative threads (Lloyd, 1993; Wollheim, 1984).

Conceived in this way, self-narration is necessary for self-governance, that is, the successful pursuit of one's values, because it provides a way to understand how the past led to the present and, therefore, a way to reasonably specify plans and expectations. Without such an understanding, the agent does not know why things happen or how to respond reasonably (Mackenzie \& Poltera, 2010; Phillips, 2003). Self-narratives, therefore, provide some basis for imagining realistically achievable 
projections that best further one's values (Lindemann Nelson, 2001; Mackenzie, 2008). However, as we show elsewhere in this paper, having a self-narrative is not sufficient for self-governance because one can disvalue one's self-narrative. ${ }^{2}$

\section{INTERSUBJECTIVE INFLUENCES ON SELF-NARRATION}

All people depend on co-authoring to develop and maintain a self-narrative. Indeed, "we are never more (and sometimes less) than the coauthors of our own narratives" (MacIntyre, 1984, p. 2016). As children, we rely on caregivers to teach us narrative archetypes. For example, we learn about heroes, victims, and villains, what motivates them, their qualities, how they develop, and what happens to them. These archetypes help us to understand what we can become and how, so that children deprived of stories are left "unscripted, anxious stutterers in their action as in their words" (MacIntyre, 1984, p. 2016). Furthermore, by the time we begin to self-narrate, we discover that many threads of our own selfnarrative have already been developed by others and are waiting for us to adopt. We are members of a particular family in a certain place and saddled with certain expectations. Even as adults, we rarely self-narrate completely from scratch; rather, we continue to draw on the cultural store of narrative archetypes and the more specific narratives others provide for us (Cocking \& Kennett, 1998; MacIntyre, 1984). This is especially the case when we face an unfamiliar experience. Consider a terminal cancer diagnosis, for example. Archetypes suggest the patient might feel anger, be in denial, write a 'bucket list,' or discover a heightened value in everyday activities. Archetypes suggest self-interpretations that the agent should be sensitive to and actions that should be considered or rejected; feelings and actions that are excluded from archetypes are implicitly discouraged. The narrative archetypes of addiction suggest to the addicted person that she will face powerful cravings, lack self-respect, suffer from poor health, be untrustworthy, and so on. There are also narrative archetypes of recovery from addiction. Hänninen and Koski-Jännes (1999) have identified several kinds, the most well-known of these comes from
Twelve-Step programs, where one has to hit rock bottom before recovery becomes possible through accepting a higher power in one's life. Given the co-authoring involved in the treatment of addiction, it is not surprising that the self-narratives of those in treatment tend to parallel the narrative archetypes provided by the treatment (McIntosh \& McKeganey, 2000, p. 1508). Even when we develop novel self-narrative content, we look to others to verify that content and we reconsider and often revise that content when it is challenged. In rare cases, it may be possible for people to successfully self-narrate in ways that are incorrectly rejected by everybody. However, such self-narration would be much more difficult than self-narrating in more socially acceptable ways. In short, we rely on co-authoring throughout our lives to facilitate both self-understanding and being understood by others.

\section{Motivational EfFects of SELF-NARRATIVES}

The process by which self-narratives are constructed over time has important implications for how easily we can change them. Although any self-narrative thread begins as merely a potential candidate for inclusion in the self-narrative, over time, certain narrative threads are consistently intersubjectively verified and entrenched within a network of other verified threads. The agent and her peers then take these established threads to represent facts about who the agent is and who she can hope to become. The implicit psychological pressure to self-narrate in accordance with these perceived facts stems from three sources. First, self-narrating contrary to facts tends to damage diachronic agency because inaccurate imaginative projections undermine goal attainment. It feels self-destructive to undermine one's diachronic agency because it is essential for creating or shaping oneself. Second, agents value self-knowledge for its own sake (Christman, 2008). The established self-narrative is taken to represent self-knowledge so adopting contrary self-narrative threads feels self-deceptive. Third, the agent's peers, given their own interest in the truth, will tend to challenge or reject the agent's self-narration if it strays too far from her estab- 
lished self-narrative. Agents value social inclusion which, among other things, requires that they give weight to the co-authoring of their peers (Cocking \& Kennett, 1998). In summary, the less plausible it is that a new narrative thread can be a continuation of the established self-narrative, the greater the feelings of self-alienation from undermining one's diachronic agency, self-knowledge, and social position. These feelings of alienation tend to generate the intuition that the narrative projection under consideration "just isn't me."

When the agent's established self-narrative aligns with all her values (i.e., not just the values implicitly entrenching the established narrative), the negative feelings of going against the established self-narrative support self-governance. However, to the extent that the agent's values (e.g., recovery from addiction) conflict with the action recommended by her established self-narrative (e.g., continuing drug use), the motivational force of the established self-narrative undermines self-governance. ${ }^{3}$ Of course, there are feelings of alienation when agents act contrary to any of their values, so why isn't the alienation of failing to pursue a valued recovery sufficient to motivate recovery as some have claimed (Downey, Rosengren, \& Donovan, 2000; Weisz, 1996)? According to our view, the reason is that, no matter how much one explicitly values recovery, one also values the things implicitly represented by the established self-narrative-diachronic agency, self-knowledge, and social inclusion. As a result, it can feel more alienating to act contrary to one's established selfnarrative despite the fact that it excludes some things that one values highly. Although established addiction self-narratives poorly express the values of diachronic agency, self-knowledge, and social inclusion, a diminished expression of value is better than its complete loss, which is what one risks if one self-narrates without regard for the established self-narrative.

\section{Narrative Work: Resolving Conflicts between Values and Self-Narrative}

When a self-narrative thread under consideration generates feelings of alienation and an intuition that it is "not me," one can take that intuition at face value and reject the thread, or one can expend the cognitive effort to explicitly assess the source of that intuition. Reflection might reveal which aspects of one's established self-narrative conflict with the narrative thread under consideration. Further assessment involves interrogating those aspects of one's established self-narrative. Are they really mutually exclusive of the new thread? Are they really factual, that is, really essential for diachronic agency, selfknowledge, and social inclusion? This process of assessment is necessarily creative and can be thought of as 'narrative work.' When assessing whether an alien-seeming thread can be plausibly integrated in her self-narrative, the agent needs to imagine plausible narrative connections between who she is now and who she would be in the future if she enacted that narrative thread. This involves means-ends planning (bow would someone like me go about successfully pursuing that end?), but it also involves making sense of the narrative trajectory (why would someone like me go about pursuing that end?). Through this narrative work, she might be surprised to find that there is a plausible path toward achieving the goal for someone like her after all. In parallel to this, the agent might also reinterpret the conflicting aspects of her established self-narrative so that it can more plausibly accommodate the goal. Reflection on her past might reveal an alternative interpretation that can also make sense of events (e.g., one was not a victim but a survivor). Once those reinterpretations are made, the existing self-narrative might be more amenable to the narrative thread under assessment. As a result of this narrative work, the agent might find that a narrative thread which initially felt alien is actually sufficiently plausible to try and integrate it in her self-narrative. If not, she must judge that the conflict between the value of the new narrative thread and those implicit in the established self-narrative is real. This entails that pursuit of the new narrative thread is unrealistic for someone like her, so her initial intuition to reject it and act in accordance with her established self-narrative was correct. ${ }^{4}$ For a more detailed discussion of the cognitive efforts required in selfnarrative change and why they are not reducible to intentional planning see Mackenzie (2008) and McConnell (2016). 
The narrative work required to change disvalued aspects of one's established self-narrative is not over at the point the agent tentatively adopts the new narrative projection. Whether a new narrative thread is ultimately integrated more permanently in the wider self-narrative depends on successfully enacting it and convincing others of its truth. In addition to all the usual challenges to agency, this involves resisting the temptation to prematurely abandon the new narrative threads for the old established narrative. When someone is trying to enact a new narrative thread that is inconsistent with the old, more established narrative, any actions or events that favor the established narrative over the new narrative loom much larger (e.g., lapses in abstinence or being called a "junkie" in the street). Both the agent and her peers are likely to quickly judge that the old narrative remains true. Comparatively, if the agent has a lapse in enacting an established self-narrative, it is much easier to convince herself and others that the lapse does not threaten the truth of her self-narrative.

The amount of narrative work required in narrative change is fixed by the disparity between the potential narrative thread and the established self-narrative. The less compatible a new thread is with the established self-narrative, the more narrative work it takes to convince oneself and others of its truth. Without doing this narrative work, the agent continues to enact her existing self-narrative because, even if she disvalues aspects of that narrative, at least it supports a degree of diachronic agency, self-knowledge, and social inclusion. ${ }^{5}$ If the above view of self-narrative development and change is correct, we would expect to find evidence of agents struggling to adjust their established self-narratives whenever they were attempting to enact life transformations. Given that recovery from addiction is one of the more pressing self-transformative challenges in health care, it is important that we investigate this selfnarrative aspect of it.

\section{Our Study: Methodology}

In 2011, we began a qualitative cohort followup study of substance-dependent people, recruiting participants at a detox facility and opioid replace- ment treatment facility in Sydney, Australia. At baseline, we interviewed 69 respondents who were between 23 and 64 years of age; 35 were male and 34 were female. The substances they were seeking treatment for were alcohol $(n=32)$, opioids $(n=$ $35)$, and amphetamines $(n=7)$; some respondents were in treatment for multiple substances. Twentyeight of the respondents were re-interviewed both 1 and 2 years from baseline, twenty respondents were interviewed roughly 3 years from baseline. Eighteen people completed all four interviews and thirty-three people completed at least two interviews. In total, 145 interviews were conducted.

At baseline we asked them, using a timeline, to narrate their life story so far. Respondents were prompted to describe their lives before they started using substances, when and why they started using substances, when their substance use became a problem, what their hopes and plans for the future used to be and what they are now, what they find important in life, and where they expect to be in 1 years' time. At follow-up interviews, participants were prompted to reflect on where they were at that moment in life, how it differed from where they expected to be a year ago, and if they were happy with where they were. All the interviews were transcribed verbatim and analyzed with Nvivo software.

Given that recovery and self-narrative transformation are long-duration phenomena, our study is limited by its relatively short, 3-year timeframe. It would be impossible to say with any certainty that any of our study participants had entered a stable, long-lasting recovery during this period. Therefore, we do not have any participants whom we could argue recovered through narrative work. Neither can we say that any participant would have recovered if only they had undertaken more narrative work. Given the shorter timeframe of our study, we have the more modest aim of illustrating the ways in which self-narratives influence the many small steps toward recovery and the lapses that sometimes lead to full-blown relapse. The design of our study is suited to investigate the role of self-narration in this detail because the frequency of in-depth interviews conducted over the 3 years elicited ample self-narrative content from each participant. 


\section{Our Study: Narrative INFLUENCES ON RECOVERY}

\section{IDENTIFICATION WITH ESTABLISHED BUT Disvalued Self-Narratives}

By the time addicted people seek treatment, they typically disvalue several aspects of their established self-narratives. At the very least, they disvalue the extent to which drug use dominates their lives at the expense of things they value more highly, such as closer relationships with friends and family, a career, and better health. It is also common for disvalued behaviors that support drug use to have become entrenched in the self-narrative, for example, stealing, lying, prostitution, taking advantage of others' trust, and so on. For example, consider how Joshua, one of our study participants, narrates the development of his addiction:

It's like at first you use it for security sort of. Yeah like it's a bit of a party thing or whatever and then you get a habit and then you start to really degrade yourself and do things you never thought to get the money 'cause it's quick, easy money. And then you start using the heroin to forget about how you got the money. It's everyday you're doing things you don't want to do to get the money to forget about what you've just done and it goes on and on and on. (Joshua)

As this kind of self-narrative becomes established, it is increasingly difficult to believe that more valued futures involving recovery from addiction, a happy family, high self-esteem, a stable job, and so on, are achievable. The amount of narrative work required to plausibly link the current selfnarrative with those valued futures is daunting. Comparatively few paths to recovery seem possible and, even then, they seem relatively implausible.

We claim that the cumulative verification of the addiction self-narrative leads addicted people to identify with it despite disvaluing it. We found some evidence of that among our participants. Nicole's addiction self-narrative is so deeply entrenched that she assumes she is instantly recognizable as an addict.

I was worried about what other people were thinking about me and you know being an addict and... I think that they can see it, you know? (Nicole)
Whether other people view Nicole this way or not, Nicole clearly cannot hide from her own self-narrative, which continues to guide how she interprets and responds to the world. A confronting incident at university is particularly revealing:

I was in the library and I felt like everyone was laughing at me which is really weird. And I think they probably were, not really but I don't know and it doesn't really matter but so I had an outburst and I told some ... another student off. . . . I was very embarrassed because I looked like a crazy person and it was my old self you know. (Nicole)

The reactions of the other students and the professor would, presumably, have been sufficiently general to verify a number of potential narrative threads that would make sense of this overly sensitive and aggressive behavior. However, from Nicole's perspective, it seems that their reactions reinforce the specific, detailed set of disvalued narrative threads that Nicole would like to be her "old self," but clearly continue to be part of her present self. In this incident, Nicole's established addiction self-narrative not only guides her initial interpretation of the situation and her response, but it also guides her interpretation of the subsequent co-authoring in a way which reinforces those disvalued narrative threads. When the established addiction narrative regularly self-reinforces in this way, it is much harder to convince oneself that recovery-directed narrative threads contrary to that established self-narrative could be true.

The challenge of narrative change is made even more difficult by the fact that the established self-narratives of addicted people are frequently fatalistic. Joshua characterizes his ongoing drug use as something that happens to him rather than something he does, "it goes on and on and on." When asked where he saw himself in one year's time, Howard said, "Probably exactly where I am now. Exactly where I am now." Similarly, John said, "I've been trying to change my life heaps but I haven't... I always end up ... back here, you know?" These self-narratives support the idea that the agent is trapped in cycles of drug use from which they are powerless to escape. Assuming that a recovered future is incompatible with such fatalism, these addicted people will have to do even more narrative work to recover. They either must narrate a plausible story of how they will 
reestablish agential power or reinterpret the past in such a way that they never actually lost that agential power.

\section{Alienation and Implausibility of Narrating Contrary to Established SELF-NARrative}

We also found some suggestive evidence supporting our claim that self-narrating contrary to one's established self-narrative will feel alien to the agent and appear implausible to him and his peers.

I feel myself when I'm using and it's when I don't use... I don't feel myself. (...) But I'm trying to ... find myself without using, it's hard. (Hayden)

I was using for so long, more than half my life, and what I thought was normal in all that time I was using, so I don't really know if I'm normal now, it hasn't been that long that I've been trying to get straight. (Craig)

We suspect that Hayden and Craig do not 'feel themselves' because they are 'trying to find themselves' in unfamiliar self-narratives (without denying that narrative-independent, physiological changes will also contribute to these alien feelings). As long as recovery-directed narrative threads feel alien, the agent will be tempted to abandon them for the relative familiarity of the established addiction self-narrative. He may then decide to try and recover again, oscillating between two incompatible narrative networks-one moment living in the old narrative, the next trying to live according to the nascent recovery narrative. ${ }^{6}$ This oscillation will tend to undermine recovery because even short periods of enacting the addiction narrative can severely damage the plausibility of what was already a relatively implausible narrative projection.

Diana reveals the effect that repeated relapse can have on other's perception of the addicted person.

People's perception of me is so important now because I've ruined half of it. And I don't deny that that's my doing but to have them believe in me again is so important. And I can't even look at you in the eye 'cause I wonder if you think I'm even telling you the truth. This is how I feel... I'm so scared that people are going to judge me that I don't know whether ... what I'm saying is worth it or not. (Diana)
Diana recognizes the need for others to verify her self-narration, that is, to "believe in her," and laments the fact that her established self-narrative of repeated relapse makes it hard for others to take her recovery-directed self-narrative seriously. Even worse, her established self-narrative guides her expectation that others see what she says as worthless no matter the content. Her established self-narrative is not just at odds with recovery, it is at odds with being a reliable self-author. In these cases, recovery also requires a plausible narrative projection of how powers of self-authorization will be re-established (Kennett, McConnell, \& Snoek, n.d.).

As discussed, one cannot do much narrative work in social isolation. One needs co-authors to verify and challenge new self-narration, to support its development and guide its accuracy. Hence the value, often referred to by people who have recovered, of surrounding oneself with co-authors who are supportive of the process of narrative change (Hänninen \& Koski-Jännes, 1999; Lewis, 2012). Unfortunately, addicted people face strong stigma and have often alienated the supportive co-authors they need:

You're a drug addict person. People look to you ... a different way ... they judge you, they're scared of you... Different from ... normal people. ... You're really low, you're just like nobody. (Hien)

Clearly, when others are scared of the agent or see him as a nobody, they will not provide the supportive co-authoring required to establish the plausibility of his recovery self-narrative. Often the co-authors that remain are still part of the drug-using milieu and those co-authors may be inclined to detrimentally entrench the established narrative threads.

The other addicts ... don't want to see someone get on with their life ... they're comfortable. I don't know, it's kind of like misery loves company... I notice when I'm going well, no-one's that happy and it's like no-one wants to give you a shot when you're hanging out but when you've been clean for six months everyone wants to give you a shot... (John)

So how can someone with an established, disvalued addiction self-narrative overcome the detrimental effects of that self-narrative to suc- 
cessfully pursue recovery? The answer is through undertaking the narrative work outlined herein.

\section{Reinterpreting the Past to Support RECOVERY}

One form of narrative work is to reinterpret those aspects of the established self-narrative that render recovery-directed narrative threads implausible and alien. When trying to change fatalistic expectations, for example, one need to believe that one's "future is open, in the sense that it is something one can create and shape through choice, resolve, and will" (Pickard, 2014, p. 12). Agents can develop their belief in an open future by reinterpreting their past so that more valued projections become more plausible. Joshua could reinterpret his cycles of drug use as something that he did, rather than something that happened to him, for example. That reinterpretation indicates that he has some capacity to intervene in these cycles, making a range of recovery projections more plausible than they were.

It can also be helpful to reinterpret the aspects of one's self-narrative that have supported the value of drug use in the past. Victoria does just this in regard to the opiates that she had become addicted to as pain medication:

I still get sore legs yeah, but not like I was, so I think ... a lot of it had to do with just being in my head. ... In your head you want it [opiates] ... more than really you are in pain. It just makes you crave it. You get addicted to it so quick that you don't know what's real and what's not real anymore. (Victoria)

On her new self-narrative interpretation, she thinks that her earlier leg pain was partially imagined, a delusional exaggeration that acted as an excuse to satisfy her cravings. This new self-narrative thread suggests that opiate use will ultimately make her pain feel worse, so she can no longer use leg pain to justify opiate use. Therefore, the new self-narrative provides some protection against relapse and is more open to futures with better forms of pain management. Similarly, Nicole benefits from reinterpreting the role of ice (crystal methamphetamine) in her life, no longer seeing it as a solution for her lack of self-confidence.
[Ice] did [help], yeah, it really did. But obviously only short term. ... I think it made my mental health worse. ... I think it made me confident but in the wrong way, you know. You can't learn to be confident through ice, that's for sure...

By narrating a connection between ice and her worsening mental health, Nicole sees that selfmedication is not a good reason to use ice. Furthermore, with this new narrative interpretation, it becomes more plausible that she would pursue more effective ways of building social confidence. Indeed, this is part of her motivation for enrolling in university, a significant step toward recovery.

\section{INTEgRATING Recovery NARrative Threads with the Existing Self- NARRATIVE}

Another form of narrative work is to better integrate recovery-directed narrative threads with the existing self-narrative by developing a network of plausible narrative connections between them. This should tend to increase the plausibility of the recovery and decrease the agent's feelings of alienation from it. Nicole is supported in this process by a counselor, who encourages her to go back to university. The counselor helps co-author Nicole's recovery narrative by telling her, roughly, "You are somebody who could succeed at university." Nicole takes ownership of this new self-narrative focus by choosing the university course that suits her and making narrative connections with her existing self-narrative.

See my problem is I don't have many hobbies and I don't have many things that interest me but something that does interest me is anatomy and, you know, all that sort of medical stuff... I didn't really realize how much I enjoyed it until I went back to uni. (Nicole)

The narrative threads she forms between her past interest in anatomy and her developing recovery narrative help to reinforce that this is not just any recovery; this is her recovery. This particular connection with valued aspects of her pre-addicted life raises hope that she will also re-establish other valued characteristics that she was afraid she had lost. 
When I was younger before I used drugs, I was such a lovely caring person and thoughtful person and a loving person and I used to be very thoughtful and do things for other people without even being asked... I feel like that's who I am becoming again you know. (Nicole)

The experience of reconnecting with valued aspects of her past self-narrative might explain, in part, why she enjoys the university course so much and that enjoyment should help her to persevere with the course and recovery in general.

The development of completely new values may also support recovery; indeed, some people have been addicted from such a young age that there is relatively little in their existing narrative worth reconnecting to. However, completely new values do not provide a shortcut to the feelings of identification that can be elicited by connecting with previously established aspects of the self-narrative.

Unfortunately, when we interview Nicole 2 years from baseline, she has had a major relapse which she explains was triggered by failing a major practical examination. Arguably, her recovery narrative was focused so intently on her university course that failure in that course would be experienced as a challenge to her whole recovery. Even when her course was going well, she felt that people saw her as an addict and this incident at her practical examination seriously challenged the truth of her recovery-directed narrative. This time, she did not have the mental resources to continue to try and convince herself and others that her recovery narrative was still true of her. She could much more easily explain her failure by incorporating it in her more established addiction self-narrative, her "old self."

Despite her good progress at university, there were signs that Nicole's recovery up to this point remained highly vulnerable. She still identified strongly with being a stigmatized drug user and had been unable to resolve the incompatibility between her established drug-using narrative threads and her nascent recovery.

I find it hard to hide who I am and or where I've been or who I have been or what I've done... It's always going to be a part of who I am and I think it's really sad but it's true... I have a drug problem or had a drug problem or that I'm on Suboxone and I think it's part of who I am and I think that worries me. (Nicole)

By hiding her past, Nicole shuts it off from narrative work so that she cannot connect it with her recovery. This process created a conflict in her self-narrative, a fissure between her past self and her recovering self. As long as that conflict remained, there was a risk that she would resolve it by abandoning the more alien recovery narrative threads. If Nicole could have connected her recovery more thoroughly to her addicted past, she would have begun to dissolve the relatively independent existences of these two incompatible self-narrative networks, eliminating the conflict between them. Eventually, there would not have been a readily available addicted self-narrative to return to, but neither would there have been a perfect non-addicted narrative that completely excluded the addicted past. To this end, a particularly helpful narrative archetype for Nicole might have been what Shadd Maruna (2010) refers to as a redemption script. In a redemption script, the narrator rewrites "a shameful past into a necessary prelude to a productive and worthy life" (p. 87), where what counts as "worthy" is judged by the narrator, not some external authority. This narrative archetype provides a way to accommodate one's negative past in the self-narrative while mitigating some of the shame associated with that past. Perhaps, for example, Nicole could have become an especially caring person because of the deep sensitivity to vulnerable people she gained through her experience of addiction. ${ }^{7}$

Obviously, Nicole's difficulty in developing her recovery self-narrative was not the only factor in her relapse-she suffers from low self-esteem, cravings for ice, and she tells us in her final interview that she has been diagnosed with borderline personality disorder. However, we cannot understand the relapse as simply the result of an intense desire or an emotional response exacerbated by mental disorder because the intensity of the desire or emotion depends on her self-narrative context. Neither can we understand a return to drug use as a rational response, given the lack of alternative opportunities. A failed practical examination only means that she must repeat her third year. Nondrug-using options remain available to her, options 
that she would presumably value more highly than this relapse. Her emotional response might have clouded her judgment so that she could not see or properly evaluate all the options available to her but, again, that emotional response is influenced by her self-narrative.

Nicole's relapse could have been prevented or mitigated by a range of non-narrative interventions if the resources were available, for example, a closer and more qualified support person or group, various pharmacotherapeutic approaches, and so on. However, consideration of self-narrative effects could also have protected her from relapse in at least two ways. First, an awareness of Nicole's self-narrative would highlight the significance of the practical examination. If Nicole's support network was aware of that significance, then they could have redoubled their support efforts around that time. Second, had Nicole been better supported in the narrative work of integrating her recovery with her established self-narrative, one failure at university would have been less likely to convince her that recovery was impossible and that the old addiction narrative represented who she really was.

\section{Pervasiveness of Narrative EFFECTS in AdDiction AND Future RESEARCH}

One implication of our research is that we should expect self-narrative effects to be particularly influential and widespread in addiction. In a trivial sense, self-narrative effects will be involved in nearly all attempts at recovery. This is because almost every recovery requires some degree of agential effort (Pickard, 2012) and all exercises of agency are influenced by the established selfnarrative context. ${ }^{8}$ However, there is reason to think that many attempted recoveries would stand to benefit more substantially from a self-narrative focus in treatment. In a large subset of attempted recoveries, the addicted person has been a drug user for many years (Dennis et al., 2005). In such long-running cases, the agent has inevitably developed a multitude of self-narrative threads to understand drug-related events, to successfully access and use drugs, and to coordinate drug use with other aspects of their lives. These narrative threads will usually have been subject to longterm, cumulative social verification by others. As a result, addiction-related narrative threads typically become well-established in the self-narrative and make up a considerable proportion of the self-narrative. People usually start to become concerned about their drug use when it begins to impinge on their other values. Eventually, their inability to protect their non-drug-using values drives them to seek treatment despite the associated stigma. So, by the time people present for treatment, they have usually been struggling with their addiction for some time. During that struggle, they will have typically created numerous narrative threads to justify and explain their behavior, so that many aspects of their lives have come to be understood and shaped in relation to drug use. Therefore, well-established, addiction-related narrative threads will pervade the self-narratives of most long-term drug users who are seeking treatment. However, the group whose self-narratives will be most dominated by addiction-related narrative threads are those, all too common, cases who have gone through multiple rounds of failed treatment (Dennis et al., 2005). For each unsuccessful round of treatment, the agent tries to understand why he failed to recover. Such failures despite professional treatment drive the agent toward more thoroughly hopeless and fatalistic self-understandings. In summary, self-narrative effects on recovery from addiction are likely to be at their strongest in longer running addictions, especially those characterized by long struggles to balance one's values and failed rounds of treatment. Such cases are common and, therefore, we would expect a wide range of addicted people to benefit from a narrative complement to treatment.

Future research should investigate whether various interventions are effective in supporting the agent complete the necessary narrative work required for recovery. For example, it would be useful to discover which narrative archetypes are best given the individual's situation and which interventions increase the rate at which people successfully adopt recovery-directed narratives. Another line of research should investigate the efficacy of narrative therapy (White, 2007; White \& 
Epston, 1990) for the treatment of addiction. Narrative therapy supports what we have been calling 'narrative work' in a variety of ways. Briefly, clients are asked to recall a situation in which they handled their addiction in a self-controlled way, for example, successfully resisting an episode of craving. The counselor then encourages the client to elaborate on why this attempt was successful, to develop an alternative narrative in which their capacities to control their substance use is made central. When addicted persons become sensitive to episodes in their lives where they coped successfully, it becomes possible for them to imagine "new endings to painful and repetitive stories" (Singer, 2001, p. 389). It would be tempting to use narrative therapy as the narrative-focused complement to addiction treatment because it is an established therapeutic system with a body of trained practitioners. However, despite a few suggestive case studies, its efficacy has not been properly investigated (Butt, 2011; Man-kwong, 2004; Poole, Gardner, Flower, \& Cooper, 2009; Singer, 2001). We agree with Hutto and Gallagher (2017) that narrative therapy could be improved in several ways, including eschewing a post-structuralist view of the self and being more open to empirical assessment. In any case, narrative Therapy is only one of several possible narrative-based therapeutic approaches and we should remain open to other styles of narrative intervention should they be developed.

\section{Conclusions}

We have explained how established self-narratives can hinder self-governance. People strongly identify with aspects of their self-narratives that have become established through consistent verification. Future possibilities that would be contrary to the established self-narrative then seem to be implausible and feel alien. When disvalued selfnarratives become established, people are motivated to enact those self-narratives rather than pursue more highly valued possibilities because the established self-narrative represents who they take themselves to be. We have also explained how selfgovernance can be reestablished through narrative work, that is, the cognitively effortful process of narrating connections between a valued future and one's self-narrative. When successful, narrative work integrates the valued future with the self-narrative in such a way that it feels less alien and seems to be more plausible. The amount of narrative work required to regain self-governance depends on the disparity between the established self-narrative and the valued future. People do not always succeed in this narrative work because it can demand too much time and effort. If our empirically informed account of the relationship between self-narratives, self-narrative work, and self-governance is plausible, it represents an important step in responding to the skeptical concern that self-narration is only ever descriptive. However, randomized, controlled trials would be needed to draw any more definite conclusions.

Addicted people often disvalue aspects of their established self-narratives, especially in longrunning addiction, when they have been through failed rounds of treatment. If our account is correct, these established self-narratives undermine self-governance by making recovery-directed narrative threads feel alien and seem implausible. As a result, addicted people have a default motivation to enact their disvalued self-narratives because it least represents who they take themselves to be. Consequently, many addicted people would benefit if they received support for the narrative work required to connect their established selfnarratives with recovery. This leads us to conclude that existing forms of addiction treatment will tend to be more effective and efficient if they are complemented by narrative-focused interventions.

\section{Notes}

1. For our purposes, we assume that the agent's evaluative judgement correctly identifies her authentic values. Clearly, this is not always true, but it will usually be the case in long-term, self-destructive addiction where the agent consistently claims to value a non-addicted life (Kennett, 2013).

2. The main claims of this paper would also be consistent with views that see narratives as having a lesser role in shaping who we are. For example, if one defined narrative more narrowly than we do here, then self-narration and its motivational effects would be less ubiquitous. However, to the extent that self-narratives continued to feature in cognition, we would expect them 
to influence self-governance in the ways we describe. For arguments that support conceiving of self-narratives as we do here see Schechtman (2007) and Velleman (2005).

3. We do not deny that the agent's evaluative judgement can be wrong and, in such cases, it would be possible that the agent's self-narrative more accurately represents her authentic values. We think that such cases will be rare in those who claim to value recovery over their long-term addiction, so we set them aside.

4. In some cases, perhaps outright false self-narrative reinterpretations will ultimately support attaining one's values. Presumably this happens with successful 'fake it 'til you make it' strategies. See, for example, McConnell and Snoek (2012). The potential success of these approaches show that a self-narrative thread only needs to be perceived as true and does not have to align with objective truth to become beneficially incorporated in a self-narrative.

5. The agent's appetite and capacity for narrative work depend on a range of factors, including belief in her own agency, self-esteem, optimism, powers of reasoning, discursive skill, and so on. Therefore, some agents will find self-narrative change easier than others. However, it is important to note that those factors are not independent of the content of the self-narrative. Sometimes the work of narrative change will involve changing a self-narrative where it does not make sense to have optimism, for example, to one where optimism makes more sense.

6. Neil Levy (2014) has suggested that addiction is a disorder of belief (rather than desire), characterized by the involuntary oscillation between believing that drug use is the best course of action and believing that it is not. We suggest that this oscillation can be controlled to some extent by adjusting the narrative networks in which those beliefs reside. The belief that using drugs is the best course of action will tend to seem implausible once the established addiction self-narrative has been sufficiently reshaped.

7. In our view, redemption narratives of the kind Maruna specifies are just one way to connect a recovery with one's past. Any archetype that can plausibly link the recovery with the existing self-narrative should work, for example, those described by Hänninen and Koski-Jännes (1999). The centrality of redemption in recovery depends on how broadly one defines redemption. If any narrative of a positive future emerging from a negative past counts as redemption, which is the definition Dunlop and Tracy (2013) use, then perhaps most recoveries will be redemptive. But, even then, we would not want to rule out other possible archetypes, for example, where addiction is interpreted as having been the best response to extreme circumstances, but then became unsuitable once circumstances changed.
8. There might be some cases where recovery is completely attributable to environmental change, for example, the Vietnam veterans who recovered from opiate addiction upon returning home; see Robins, Helzer, Hesselbrock, and Wish (2010) Similarly, we might develop physiological interventions that prevent cravings or 'highs' so successfully that recovery needs no further agential input. However, these paths to successful recovery are rare. The recovery-promoting environment that the Vietnam veterans enjoyed is unavailable to most. Physiological interventions, in contrast, are often available but, as of yet, are rarely fully effective on their own.

\section{REFERENCES}

Biernacki, P. (1986). Pathways from heroin addiction: Recovery without treatment. Philadelphia: Temple University Press.

Birnbaum, H. G., White, A. G., Schiller, M., Waldman, T., Cleveland, J. M., \& Roland, C. L. (2011). Societal Costs of prescription opioid abuse, dependence, and misuse in the United States. Pain Medicine, 12, 657-67.

Brandon, T., Vidrine, J., \& Litvin, E. (2007). Relapse and relapse prevention. Annual Review of Clinical Psychology, 3, 257-84.

Butt, M. M. (2011). Using narrative therapy to respond to addiction: An experience of practice in Pakistan. International Journal of Narrative Therapy o Community Work, 2, 51-61.

Christman, J. (2008). Why search for lost time? Memory, autonomy, and practical reason. In K. Atkins \& C. Mackenzie (Eds.), Practical identity and narrative agency (pp. 146-66). New York: Routledge.

Cocking, D., \& Kennett, J. (1998). Friendship and the self. Ethics, 108, 502.

Dennis, M. L., Scott, C. K., Funk, R., \& Foss, M. A. (2005). The duration and correlates of addiction and treatment careers. Journal of Substance Abuse Treatment, 28 (2 Suppl.).

Downey, L., Rosengren, D., \& Donovan, D. (2000). To thine own self be true: Self-concept and motivation for abstinence among substance users. Addictive Behaviors, 25, 743-57.

Dunlop, W. L., \& Tracy, J. L. (2013). Sobering stories: Narratives of self-redemption predict behavioral change and improved health among recovering alcoholics. Journal of Personality and Social Psychology, 104, 576-90.

Hänninen, V., \& Koski-Jännes, A. (1999). Narratives of recovery from addictive behaviors. Addiction, 94, 1837-48.

Heyman, G. (2009). Addiction: A disorder of choice. Harvard: Harvard University Press. 
Hutto, D., \& Gallagher, S. (2017). Re-Authoring narrative therapy: Improving our self-management tools. Philosophy, Psychiatry, and Psychology, 24, 157-67.

Kellog, S. (1993). Identity and recovery. Psychotherapy, 30, 235-43.

Kennett, J. (2013). Just say no? Addiction and the elements of control. In N. Levy (Ed.), Addiction and self-control (pp. 144-64). Oxford: Oxford University Press.

Kennett, J., McConnell, D., \& Snoek, A. (n.d.). Reactive attitudes, relationships, and addiction. In $\mathrm{H}$. Pickard \& S. Ahmed (Eds.), Routledge handbook of the philosophy and science of addiction. London: Routledge.

Koski-Jannes, A. (2002). Social and personal identity projects in the recovery from addictive behaviors. Addiction Research and Theory, 10, 183-202.

Levy, N. (2014). Addiction as a disorder of belief. Biology \& Philosophy, 1-19.

Lewis, M. (2012). Why addiction is NOT a brain disease. Available from: http://blogs.plos.org/ mindthebrain/2012/11/12/why-addiction-is-not-abrain-disease/.

Lindemann Nelson, H. (2001). Damaged identities, narrative repair. Ithaca, NY: Cornell University Press.

Lloyd, G. (1993). Being in TIME: Selves and narrators in philosophy and literature. London: Routledge.

MacIntyre, A. (1984). After virtue: A study in moral theory (2nd ed.). New York: Oxford University Press.

Mackenzie, C. (2008). Imagination, identity and selftransformation. In K. Atkins \& C. Mackenzie (Eds.), Practical identity and narrative agency (pp. 121-45). New York: Routledge.

Mackenzie, C., \& Poltera, J. (2010). Narrative Integration, fragmented selves, and autonomy. Hypatia, $25,31-54$.

Man-kwong, H. (2004). Overcoming craving: The use of narrative practices in breaking drug habits. International Journal of Narrative Therapy \& Community Work, 1, 17-24.

Maruna, S. (2010). Making good-How ex-convicts reform and rebuild their lives. Washington, DC: American Psychological Association.

McConnell, D. (2016). Narrative self-constitution and recovery from addiction. American Philosophical Quarterly, 53, 307-22.

McConnell, D., \& Snoek, A. (2012). Narrating truths worth living: Addiction narratives. AJOB Neuroscience, 3, 77-8.

McIntosh, J., \& McKeganey, N. (2000). Addicts' narratives of recovery from drug use: constructing a non-addict identity. Social Science \& Medicine, 50, 1501-10.
Mohapatra, S., Patra, J., Popova, S., Duhig, A., \& Rehm, J. (2010). Social cost of heavy drinking and alcohol dependence in high-income countries. International Journal of Public Health, 55, 149-157.

Orford, J., Velleman, R., Natera, G., Templeton, L., \& Copello, A. (2013). Addiction in the family is a major but neglected contributor to the global burden of adult ill-health. Social Science and Medicine, $78,70-7$.

Phillips, J. (2003). Psychopathology and the narrative self. Philosophy, Psychiatry, and Psychology, 10, 313-28.

Pickard, H. (2012). The purpose in chronic addiction. AJOB Neuroscience, 3, 40-9.

Pickard, H. (2014). Stories of recovery: The role of narrative and hope in overcoming PTSD and PD. In J. Z. Sadler, B. Fulford, \& C. Werendly van Staden (Eds.), The Oxford handbook of psychiatric ethics. Oxford, UK: Oxford University Press.

Poole, J., Gardner, P., Flower, M. C., \& Cooper, C. (2009). Narrative therapy, older adults, and group work? Practice, research, and recommendations. Social Work With Groups, 32, 288-302.

Robins, L., Helzer, J. E., Hesselbrock, M., \& Wish, E. (2010). Vietnam veterans three years after Vietnam: How our study changed our view of heroin. American Journal on Addictions, 19, 203-11.

Schechtman, M. (2007). Stories, lives, and basic survival: A refinement and defense of the narrative view. Royal Institute of Philosophy Supplement, 82, 155-78.

Shadel, W. G., Mermelstein, R., \& Borelli, B. (1996). Self-concept changes over time in cognitive-behavioural treatment for smoking cessation. Addictive Behaviors, 21, 659-663.

Shinebourne, P., \& Smith, J. A. (2009). Alcohol and the self : An interpretative phenomenological analysis of the experience of addiction and its impact on the sense of self and identity. Addiction Research and Theory, 17, 152-67.

Singer, J. A. (2001). Living in the amber cloud: A life story analysis of a heroin addict. In P. McAdams, R. Josselson, \& A. Lieblich (Eds.), Turns in the road: Narrative studies of lives in transition (pp. 253-77). Washington, DC: American Psychological Association.

Stanford, M., Banerjee, K., \& Garner, R. (2010). Chronic care and addictions treatment: A feasibility study on the implementation of posttreatment continuing recovery monitoring. Journal of Psychoactive Drugs, Suppl 6, 295-302.

Velleman, J. D. (2005). Self as narrator. In J. Christman $\& \mathrm{~J}$. Anderson (Eds.), Autonomy and the challenges 
to liberalism: New essays (pp. 56-76). Cambridge: Cambridge University.

Walters, G. D. (1996). Addiction and identity: Exploring the possibility of a relationship. Psychology of Addictive Behaviors, 10, 9-17.

Weisz, C. (1996). Social identities and response to treatment for alcohol and cocaine abuse. Addictive Behaviors, 21, 445-58.

West, R. (2006). Theory of addiction. Oxford, UK: Blackwell.
White, M. (2007). Maps of narrative practice. New York: W.W. Norton.

White, M., \& Epston, D. (1990). Narrative means to therapeutic ends. New York: W. W. Norton and Company.

Wollheim, R. (1984). The thread of life. Cambridge: Cambridge University Press. 